University of Delaware

Disaster Research Center

PREIIMINARY PAPER

\#187

ORGANIZATIONAL RESPONSE TO THE MEXICO CITY EARTHQUAKE OF 1985: CHARACTERISTICS AND IMPLICATIONS

E. L. Quarantelli

1992 
ORGANIZATIONAL RESPONSE TO THE

MEXICO CITY EARTHQUARE OF 1985:

CHARACTERISTICS AND IMPLICATIONS

E. I. Quarantelli

Disaster Research Center

University of Delaware

Newark, Delaware 19716 USA 


\title{
ORGANIZATIONAL RESPONSE TO THE MEXICO CITY EARTHQUARE OF 1985: CHARACTERISTICS AND IMPLICATIONS
}

\begin{abstract}
A study involving a collaborative effort between American and Mexican social scientists was made of the individual and organizational response to the 1985 earthquake in Mexico city. Our general findings only about the organizational activities are summarized under five general themes: (I) the massive and complex organizational response was decentralized, (2) resources for organizations were not problematical but there were difficulties in their quick and effective use, (3) the dominant organizational behavior was emergent rather than traditional, (4) organizational personnel carried out their work and occupational roles, and (5) there was changes in disaster planning of organizations as a result of the disaster. Both practical and theoretical implications of our research findings are noted.
\end{abstract}




\section{Introduction}

This paper reports on part of a larger social science study of the response to the Mexico City earthquake of 1985. The Disaster Research Center (DRC) in the United States in cooperation with Mexican colleagues, undertook field research on both organizational and individual behavior in the aftermath of the disaster in the largest urban complex in the world. Since the observations made about the behavior of individuals have been published elsewhere, this paper summarizes only our findings about the characteristics of the organizational responses in the earthquake, and also some of the implications of those conclusions.

\section{Sources of Data and Data Collection}

Earthquakes have been noted in history as far back as oral and written records go. But studies of a systematic nature of the more social aspects of such disasters are a very recent phenomena. Inventories of the relevant literature credit research at the University of Chicago done on the 1952 Bakersfield, California earthquake, as the first field study of its kind (A preliminary report, 1954). The most complete inventory of such work up to 1979 lists only 26 other studies done by social scientists of such occasions as the Alaskan, Niigata, Chilean, Western Sicily, Gediz, Banja Luka, Peruvian, 1971 southern California, Managua, Guatemala City and Friuli earthquakes (Quarantelli, 1984b). However, the great majority of such work had not either been systematic, done immediately after the disaster and/or of a large urban area. Thus, we had little direct guidance from previous social research on earthquakes on how to proceed in our study of the Mexican city disaster. (Since 1985 there has been somewhat of an acceleration of field work in such earthquakes as the Campania Baslicata in Italy, the Armenian, and especially Loma Prieta, although this is all research initiated after our own study was concluded).

But there is a rather substantial literature from nearly 40 years of research on other kinds of disasters (see Kreps, 1984, 1985), and DRC used that in its approach. We decided to concentrate primarily on the emergency time period reactions and the immediate postimpact response, and secondarily on whatever longer run social effects we could study. This still left us with many research possibilities. After discussions with our Mexican colleagues we eventually centered on two different but related aspects.

on the one hand, we launched a study of the emergency time response of organizations in Mexico City to the earthquake; this was partly dictated by the fact that DRC has over the years undertaken extensive studies of organizational responses to disasters (see, e.g., Warheit and Dynes, 1968; Dynes, 1974; Dynes, Quarantelli and Kreps, 1981; Quarantelli, 1990). On the other hand, we also made a decision to study behavior at the individual or human level; in particular this was seen as providing the possibility of carrying out systematic social science surveys of a metropolitan population involved in a disaster, a rather rare research undertaking up to 
the present time (for the survey findings, see Quarantelli, 1992).

With the assistance of our Mexican colleagues, DRC obtained two major sets of primary data on organizational behavior: in-depth interview protocols and documentary material.

The in-depth interview protocols. La Facultad Latinoamericana de Ciencias Sociales (FLACSO) obtained over three dozen in depth interviews of organizational officials who played major roles in the disaster. DRC drafted the initial interview guide, provided field training in Mexico for the Mexican students who actually conducted the interviews, and recommended who should be interviewed in which organizations. While not formally intended to be a longitudinal study, because the interviews were conducted over a number of months in the year following the earthquake it was possible to obtain information not only on emergency time response but also on the recovery activities of the involved organizations.

There were lengthy, formal interviews with over 20 representatives in various subunits of the Mayor's office (what we later call the DDF) involved in such varied tasks as policy formation, public information, urban planning, medical services, public works, police and fire operations, hydraulic systems, transportation, legal services, utilities, morgue operations, the office of civil protection, and from representatives of various delegaciones within the larger office, as well as activities which developed in the aftermath of the earthquake such as listing missing persons. In addition, another 17 long formal interviews were conducted with representatives from PEMEX (the Mexican national petroleum company), the Red Cross, unions of hospital workers and tenants, and federal agencies including the military. The substantive focus of all interviews was on intra and interorganizational activities and the behavior of organizational personnel.

Documentary material. Besides the in depth interviews, DRC obtained relevant information from a variety of other sources. With the help of our Mexican colleagues, we were able to acquire a number of Spanish language publications on the earthquake, some of a popular nature but some done in a social science framework. In addition, the Center collected whatever English language reports it could find on the earthquake. In all we eventually acquired about five dozen such items. This set of material proved very useful for background purposes as well as for looking at some organizational changes which occurred in the year following the earthquake.

The study design, therefore, was developed in collaboration with our colleagues in Flacso. This joint effort resulted in the development of interview instruments which allowed data collection to flow from existing theoretical understanding about the emergency time behavior of organizations and persons, but yet were adapted for the group sociocultural patterns which existed in Mexico city at the time of the earthquake. All interviewing was conducted in spanish by native speakers. The organizational interviews were 
translated under DRC supervision in the United States into English and analyzed solely at the center.

\section{The Impact of the Earthquake}

Mexico, and especially parts of the metropolitan area of Mexico City suffered a major disaster in late 1985. The interaction between two tectonic plates generated a great deal of accumulated energy which was released in two earthquakes: one on September 19, and the other on september 20 (we will not distinguish between the two in the rest of this article). The first registering 8.1 on the Richter scale occurred at 7:18 am; the second happened about 36 hours later at $7: 38 \mathrm{p} . \mathrm{m}$. on the next day registered 7.5 on the scale. Although the first epicenter was about 230 miles away, the greatest impact was in Mexico City (Esteva, 1988).

Whether looked at in general or in specific terms, the more obvious sociophysical consequences of the earthquake in Mexico City are impressive. The earthquake in all of Mexico was probably not as absolutely or relatively disruptive or damaging as the Tangshan one of 1976 in China (where over 275,000 persons died) and perhaps not even the Chilean earthquake of 1985 (where over 400,000 persons were made homeless), neither of which got anywhere near the mass media or world attention that the Mexican disaster received. Yet if the estimates are anywhere near correct, the Mexico city earthquake of 1985 was without doubt a major disaster.

In general terms, thousands of persons were killed and injured (for sources of all the statistics not otherwise cited in this paper, see Dynes, Quarantelli and Wenger, 1990). At least a hundred thousand building units, mostly residential ones, were damaged in some way. Hundreds of thousands were made homeless. Tens of millions of dollars were lost in the tourist trade and hundreds of millions in wages by workers who became unemployed as a result of the earthquake. Billions of dollars worth of material damage was done. Reconstruction and rehabilitation costs, estimated at five billion US dollars (although some estimates run as high as 10 billion, see The 1985 Mexico Earthquake, 1986), was the equivalent of about six percent of the Gross National Product (Arnold, 1989: 63). The World Bank alone provided over a half billion dollars in reconstruction loans (Kreimer, 1989). The earthquake was also the worst in terms of the overall insured loss, being exceeded only by San Francisco in 1906 and Tokyo in 1923.

Even when looked at in more specific terms the consequences are impressive. To be sure, even years after the disaster, exact statistics are lacking as to deaths, injuries, building and property destruction, economic losses or whatever usually could be measured; nevertheless overall it is clear the effects were major along a number of different lines. The destruction from the earthquake was diffuse and somewhat spatially random throughout the huge metropolitan area. But the complex nature of the subsoil 
resulted in variation in intensity as well as in damaging resonance effects. Thus, the most damage tended to be concentrated in the north central and eastern sections of the city. In those localities, certain working class neighborhoods such as Morelos, Centro, Guerrero, Doctores, Antonio Abad, Nonoalco-Tlatelolco, and certain middle class areas of Cuauhtemoc, Roma, Condesa, and Juarez were particularly hard hit. Most of the major damage was centered in three of the delegaciones, namely Benito Juarez, Gustavo Madero, and Cuauhtemoc--the last suffering the most physical damage. There were specific major pockets of destruction (e.g., 43 out of 102 apartment buildings were left unfit for living in NonoalcoTlatelolco; 80 percent of the buildings were destroyed or damaged in Morelos (Mendez, 1986: 25).

Apart from the physical damage, there were according to official statements at least five thousand people killed and 14,000 injured. our own survey findings suggest that as many as 2,000,000 residents of the capital at least temporarily moved out of their own homes. Two years after the earthquake, around 90,000 victim families had been rehoused (Storlarski and Santa Maria, 1987: 2).

other residents of the city, while their own homes were not directly affected, either lost or had their employment interrupted. For example, there is one estimate that 1,326 buildings housing more than 10,000 shops and factories, such as textile and clothing manufacturers, suffered damages (Mendez, 1986: 25). Many government agencies housed in over 240 damaged buildings did not resume normal work functioning for days or for weeks sometime (over 150,000 public employees eventually had their work location relocated elsewhere, Perez, 1987: 13). In addition, according to some reports, up to 1,687 public schools out of around 3,000 suffered structural and/or non-structural damages (de la Madrid, 1986: 5; Mendez, 1986; Armillas, 1989) interrupting the education of over 650,000 children (Robinson et al., 1986: 90). Since everyday work and school activities were badly affected, ceasing in many cases, there was a massive disruption of normal routines in the community. (see Thier, Gratton and Johnson, 1986; Gratton et al., 1987). (For initially gathered statistics, see Bohlen, 1986).

There was the additional complication that many important public services could not function normally. The central telephone exchange was damaged; one consequence was that apart from affecting local phone communication, almost all national and international long distance and telex and telegram lines were renderable inoperable. Along with damages to eight power generating substations about 1,280,000 electrical installations were damaged (de la Madrid, 1986: 5). In addition, with five destroyed and 22 damaged hospitals there was a loss of 4,260 hospitals beds, about 30 percent of existing capacity (Armillas, 1989: 3).

The Social Response 
We summarize our findings about the organizational behavior under five general themes. The specific details and statistics of what we found are elaborated in our more general and larger report on the disaster (see Dynes, Quarantelli and Wenger, 1990).

1. The initial organized emergency response was massive, complex and decentralized; although limited overall coordination only slowly developed, the decentralized groups functioned relatively effectively.

The organizational response of the public and private agencies was not only massive, but also complex. Within the public sector, agencies and departments from the national, federal district and delegaciones levels were involved. In addition, a great variety of private groups, businesses, ad voluntary organizations also launched major activities, and many new citizen groups appeared on the scene. Furthermore, millions of individual and group volunteers concurrently launched a mass assault on the problems of immediate search and rescue, casualty care, and providing aid to victims. The Mexican government additionally had to respond to more than 250 offers of aid from foreign governments, international agencies, and nongovernment organizations.

Now, researchers have observed that much of the disaster planning literature as well as actual planning uses a "command and control" model. This assumes that organizational responses in disasters need to be centralized with decision making at the top in formally authoritative positions (see Dynes, 1990). On the other hand, researchers have also long noted that the actual management of the emergency time period in disasters very rarely follows such a model. Instead organized responses in disasters tend to involve coordination much more than control, since decision making is pluralistic and decentralized at lower levels of organizations (Dynes and Quarantelli, 1977: 24). It is believed that:

the structural conditions of the emergency period makes for uncertainty, diversity, decreased formalization and decentralization

(Dynes and Aguirre, 1979: 73).

What we found in Mexico clearly was the second model. Through the first three days of the emergency period, the organizational response was dominated by a substantial amount of independent actions. With the withdrawal of the military from a very temporary lead role, it required about three days for the DDF to assume legitimacy and to establish a Metropolitan Emergency Commission to attempt some coordination of activities. During this initial period, hundreds of public and private groups handled relatively well many problems in such areas as search and rescue, sheltering, casualty care, and the restoration of services. But there was no overall coordination of this massive response, contrary to some 
outsider views that "the Government's response was rapid and coordinated" (United Nations Economic Commission, 1985: 6).

For the remainder of the two weeks following the earthquake, this pattern was modified in degree, but not in kind. Thus, the DDF assumed a more coordinative role, and the nightly meetings of the commission were critical in the organizational taking on of tasks and the sharing of information at the highest levels of the metropolitan structure. However, a "command and control" structure was never imposed, there was never a top down centralized system of decision making and operations. Illustrative of this is that no central EOC staffed around the clock was ever set up. The DDF served more as a "broker", that is, as a small, social entity that identified problem areas, provided information, located resources, and facilitated contacts between different groups. What came into being was what earlier researchers have called an "emergent resource" model of operation (Dynes, 1983). An overall inherently decentralized response pattern remained, although there were pockets of segmental coordination occurring among some organizations working at the same tasks.

While the general research literature assumes that a decentralized response is typical in disasters, there are some writings that suggest a possible qualification for what might happen in highly centralized societies, especially in developing countries. For example, Mcluckie (1975: 8) hypothesizes that in more centralized societies, emergency management will be dominated by a few positions that are high in political organizations in the system. Anderson (1969b) suggests that there is a tendency for military organizations to assume a larger role in disaster response in centralized and developing countries. Others, such as clifford (1956), have also observed an increase in centralization in organized response activities in disasters outside of the United States; in fact, he was reporting on a flood along the Rio Grande River and an hurricane disaster in Tampico, Mexico. But he also did report that there was a tendency for Mexican disaster victims to rely more heavily upon family and relatives and to be less responsive to officials than victims in the United States. Kennedy (1982) also, after looking at the organizational activity and the military describes a rather centralized and from the top down operation in a 1965 earthquake in Chile.

Why then did a decentralized response occur in the Mexico city earthquake? A number of factors are relevant. First, the demands created by the earthquake were extensive. There was major damage to the infrastructures and resources of many governmental agencies. This was unlike many disasters where the key organizations are directiy untouched and remain available to be mobilized and used in whatever way is necessary. Furthermore, while the earthquake effects were diffuse throughout the metropolitan area, the physical damage and destruction was concentrated in certain neighborhoods, 
blocks and streets, all of which fostered immediate action on the part of local, independently operating groups.

Second, certain political considerations mostly precluded the implementation of the military plan (DN-3) which formally provided for centralized control. Therefore, the response of almost all organizations was not guided by any overall planning or by a similar earlier experience. Authority and coordinative action had to be improvised, like most other aspects of the response. At the system wide level even a semblance of coordination took time; in this case, approximately three days. While intraorganizational coordination among autonomously responding groups was easier to achieve, this did not occur in all groups.

Third, and most important of all, the pattern of relationships that emerged after the earthquake was consistent with everyday patterns within the DDF and Mexico City. During routine times, public organizations and agencies within the city operate informally with considerable autonomy; there is at the operational level a decentralized system. When coordination of action did occur among agencies, such as that among federal, state and district agencies working to repair the water system and supply emergency water, it was often among those who had similar contacts during normal times. We may have initially incorrectly assumed that Mexico city was highly centralized, but with the help of our Mexican colleagues found that while there may have been official or formal centralization, at the operational level there is considerable decentralization on an everyday basis.

A practical implication of our general finding is that when officials are faced with a massive disaster that seriously disrupts lifelines, directly impacts responding groups, and is diffuse in its impact, a considerable period of decentralized organizational action should be anticipated. The most useful type of planning therefore would be attempts to develop a degree of self-sufficiency among potentially responding units and formulating measures to facilitate coordinating this initial response through time. What disaster planning agencies such as BAREPP in the San Francisco area and SCEPp in Los Angeles are attempting to develop for managing major earthquakes in California are on the right track.

There are several implications from a theoretical point of view. For one, the decentralized response in the earthquake is supportive of the principle of continuity frequently discussed in the disaster literature (e.g. Quarantelli and Dynes, 1977). This is the idea that what is in place before a disaster will continue during a disaster. However, our study in Mexico indicates that it is necessary at times to go beyond the surface: Superficially looked at, the everyday formal governmental structure in Mexico city might appear to be a top down, centralized system; looked at more closely especially from an operational point of view, even the normal system was rather decentralized. Other observers of the Mexican 
earthquake have also initially missed this point (e.g., the statement is made in Lessons from Mexico City, 1985: 1 that "the Mexico City's government is highly centralized").

Another theoretical implication is that there may be in certain disasters a relationship between the degree of centralization of a system and the degree of centralization of the organized response. our observations in the earthquake do not deny that there could be centralized responses in disasters in centralized systems; Mexico City did not have a centralized system. We need to go now beyond asserting that organized disaster responses are either centralized or not centralized to specifying especially the social structural conditions which are conducive to one or the other response pattern appearing. While we think a case can be made that most emergency time organized responses in disasters will necessarily tend to be relatively decentralized, it is not improbable, given the principle of continuity, that in centralized systems there will be some carryover from everyday patterns (and there is some implications of this in McLuckie's study of national level responses to disasters in Italy, Japan and the United States; see, 1977).

Finally, what this study also implies is that we need to obtain a better picture than we have of "loosely coupled organizational systems", the label Weick (1976) applies to such social organizational arrangements as we found in Mexico City. There would seem to be the possibility of different kinds of loosely coupled systems---there might be autonomy along a variety of different social dimensions. If so, then the consequences for disaster planning and disaster response might differ.

2. Organizational resources needed to cope with the disaster were not problematical, but there were difficulties in their quick and integrated use.

A disaster frequently conjures up images of massive damage and destruction of people and things. In fact, there often is a tendency to define disasters in terms of casualties and/or physical damages (Britton, 1987 points out this is especially so by nonsociologists), although more sophisticated conceptualizations tend to stress social vulnerabilities, social disruption and disaster occasioned needs/capabilities imbalances (see Pelanda, 1982; Quarantelli, 1985b, 1987; Drabek, 1987b; Kreps, 1989: 32). However, damage to people and things sometimes do occur on a large scale, and to some degree. in most although not all disasters. Thus, one presumed consequence of such a happening would be a lack of resources to cope with post disaster needs and demands.

However, it is clear that in Mexico city, except in very isolated instances, there was not an absence of organizational resources in the aftermath of the earthquake. That is, for most purposes or activities of organizations, they had the personnel, material, equipment, goods, etc. that they needed. There were a few 
exceptions, for example, heavy duty equipment for the later search and rescue attempts in collapsed high rise buildings (Olson and olson, 1987; Martin, 1989). But our study found no evidence that organizations generally suffered from lack of needed resources.

There are several explanations of this. When all the casualties and physical damages are added together, they constitute a minor fraction of all the people and things in Mexico city at the time of the earthquake. This can be seen even when losses in specialized matters are considered; for example, a number of physicians and nurses as well as hospital facilities were lost, but the huge size of the everyday health system which survived in the area allowed it to cope adequately with disaster generated medical needs.

In addition, there was as there always is in such occasions, a massive convergence of people and things to the disaster site. From within areas of the capital city undamaged by the earthquake, from other areas in Mexico, and from outside the country there came a flood of aid in every conceivable form that more than compensated for whatever losses in resources were suffered.

But there were serious problems with the use of personnel and goods in coping with the disaster. However, the difficulties were not in the absence of, but rather in the quick and integrated use of the available resources (we leave aside here the separate problem of unsuitable aid, such as some of the medical supplies that arrived). We did find there were often delays and slowness in getting and using resources where they were needed, both within and between organizations. Also, there was considerable lack of integration in using resources (ranging all the way from volunteer personnel searching over and over again particular sites while other locations received no systematic attention, to the relative absence of vehicles for taking dead bodes to the morgue when hundreds of ambulances went unused for that purpose).

These observations are consistent with the research literature (Drabek, 1986). In most disasters there is no quantitative lack of resources, be these people or things (information however is a different matter). But there often is slowness in getting such resources to where they are most needed. In part, this is because there is almost always serious difficulties in initial assessments of what resources are needed and where, a factor that is compounded the more the disaster impact is spatially diffuse, as to some extent was true of the earthquake in Mexico city.

Also, there typically is mass convergence of helpers and help, often by people and groups unfamiliar to one another working in an unfamiliar and confused setting. Furthermore, when organizations are involved in responding to a disaster, both their intra and interorganizational communication becomes problematical, especially in the absence of prior planning (Quarantelli, 1985a). Then, too, many groups will improvise in a variety of ways. Finally, as 
already noted, widespread decentralized decision making often occurs in organizations coping with disaster demands. All of these conditions occurred in the response to the earthquake; all hindered and retarded an overall or integrated use of available resources.

From a practical viewpoint, Mexico city again illustrates that certain response happenings are to be expected. Using available resources will be more of a problem than having to find new ones. Convergence, while helpful along some lines, often creates a resource overloaded situation. Quick decentralized decision making at lower levels of organizations, again very functional for effective on-the-scene responses, makes an integrated use of resources difficult. These are all issues which can be addressed and ameliorated by planning the management of a disaster which is different from preparing for a disaster; planning is not managing and different principles are involved as disaster researchers have pointed out (Quarantelli, 1985a).

At a more theoretical level, Mexico City illustrates again that there tends to be certain almost universal features of organizational activities and problems that are inherent in the very social nature of disasters. If so, there is some sort of balance necessary between prior planning and dependency on improvisation in a disaster response. This is a point recently strongly made by Kreps. He notes that:

effective emergency management requires both improvisation and preparedness. Absent the former, emergency management loses flexibility in the face of changing conditions. Absent the latter, emergency management loses clarity in meeting essential disaster related demands. Equally important, improvisation and preparedness go hand in hand. One need never worry that preparedness will become so rigid as to decrease the ability to improvise. Quite the opposite, the very effort to prepare, even if is only modest, increases the ability to improvise (1990: 10).

At present researchers do not know the best balance, but the disaster in Mexico City suggests the question ought to be more seriously examined than it has been up to the present time.

3. The emergency time organizational response was dominated by the activities of extending and emergent organizations and characterized by much emergent behavior.

A useful typology of organized response to disasters was developed in the early days of DRC (see quarantelli, 1966; Dynes and Quarantelli, 1968; for derivable propositions from the typology see 
Stallings, 1978). According to this typology, there are four types of organizations that respond in disasters.

First, there are established organizations who engage in their regular tasks and utilize their normal structures. These are often emergency oriented groups such as police and fire departments (although even such organizations may show a different form depending on the response to a particular disaster; see wenger, Quarantelli and Dynes, 1986). Second, expanding organizations are those groups that undertake traditional tasks, but undergo an alteration and expansion of their normal structures to do so. American Red Cross chapters and some social welfare agencies are examples of collectivities that often change in this direction in disasters. Third, extending organizations maintain their normal day-to-day internal structure, but perform nonregular or nontraditional tasks during a disaster. For example, a construction company may become involved in building demolition and debris clearance. Finally, emergent groups are organized collectivities that did not exist before the disaster. They are social entities that undertake new tasks and develop a new structure to guide their activities, e.g. an informal search and rescue team or an ad hoc coordinating committee.

In fact, a constant refrain in the disaster literature since it started to appear in the late 1950 s is that disasters are characterized by "emergent" phenomena. As Drabek (1987a) has recently noted that label covers a variety of different social activities and different theoretical issues. Quarantelli (1984a), using DRC studies of organizations, for example, has drawn a distinction between emergent groups (where there is some new social collectivity) and emergent behavior (where there is no new social entity but only new social actions).

In the Mexico City earthquake, the leading roles were played by extending organizations and emergent groups, and to a somewhat lesser extent, expanding organizations. At the highest levels of authority within both the federal and district jurisdictions, new and emergent groups came into being to handle the problems of coordination of activity. At the level of operations, extending organizations appeared as the petroleum company, subway and transportation units, certain governmental departments, private businesses and lifeline agencies undertook nontraditional tasks for themselves such as undertaking search and rescue, caring for casualties, sheltering and.feeding victims. Some major social institutions, such as the Red Cross became expanding organizations.

In addition, new informal groups of citizen volunteers and organizational representatives emerged to handle various disaster generated problems. Also particularly noticeable was the emergence of work brigades in many of the organizations. These, since they came out of the framework of traditional existing organizations, (most in fact bureaucracies) and were peopled by known co-workers, 
were not quite emergent groups, but more than emergent behavior. But in any case they were organized emergent phenomena.

Established organizations of course did not disappear. But it is interesting to note that organizations that maintained their usual structures and functions, such as the military and the police, played a limited role in the emergency time response. They undertook primarily traditional tasks for these groups, namely security and traffic control.

This extensive pattern of emergent behaviors, emergent groups and extending organizations was the result of a lack of prior disaster planning and the massive demands created by the earthquake which substantially exceeded the in place emergency response capabilities of the community. Suddenly a crisis situation existed due to an inadequate precrisis management structure and mechanisms. The unwillingness to operationalizing $\mathrm{DN}-3$ and giving the Army (an established organization) overall responsibility created a void of traditional response mechanisms. Under these conditions, new emergent and extending activities developed to meet the pressing needs of the impacted community. Similar patterns have been noted in other disaster settings (Drabek, 1986: 154-157, 160-162).

Some researchers have argued that the magnitude of a disaster can be gauged by the extent to which emergent and extending groups become involved in the response pattern. Simply put, the more the response is dominated by these kinds of organizations, the more severe the disaster (Quarantelli, 1987: 25). If this proposition is correct, it can be concluded that the earthquake in Mexico City was of great magnitude, not just in regard to its physical destruction, but with also with regard to its social disruption.

There are some important implications from the varied types of collective response that our study found. Among other things, the observed pattern suggests that prior planning must emphasize the need for groups at times of disasters to be able to improvise, to do things they normally do not do, and/or to do them in organized ways that are not usual for the organization. Traditional and established ways of doing things by usual social arrangements will not always work; the demands and needs especially in the emergency period of a major disaster often require something different of an emergent nature. In some cases what is required is even a new group doing new things, what we have called emergent groups.

From a more theoretical perspective, there are several implications about our general observation of emergence. In part, the Mexican earthquake shows that even in the absence of planning, the demands of extreme situations will force social alterations in the responses of relevant organizations. While this may be true, it does not follow that it has to be completely left up to spontaneous emergence. Good preparedness planning can anticipate much of what might be required and proceed accordingly. Not everything can be 
almost exclusively with occupants of high or relatively high level occupational roles. But in order to understand organizational behavior we had to find out what key officials themselves did. So indirectly we did obtain a picture of how top level officials personally reacted in the earthquake (we do not have an equivalent picture of middle and lower levels officials and staffs so our observation are not applicable to them).

We found that organizational officials, just as much as individual citizens, generally did not passively wait for orders or directions. In fact, it is possible to say that many of them were proactive rather than just reactive. They started to consider what effects the earthquake might have had on the operations of their organizations and what actions the group needed to undertake. often, they moved to trying to assess damages and otherwise obtaining information relevant to their organization. Basically key officials were not psychologically frozen or stunned by what was essentially a very unexpected event.

Iikewise, there were no role conflicts that behaviorally led officials to abandon or fail to assume their work responsibilities. Those on duty at the time of the earthquake, such as at the metro system remained at work although they felt concern about family members or coworkers. The psychological concern about others did not lead them to leave their jobs. Those who were not at their jobs at the time of impact, as in the Red Cross, usually thought immediately they would be needed at their place of work, and proceeded to go there as best as they could. There was not much delay in getting to work locations. Thus, whatever role conflict existed, it was resolved in favor of their organizational role.

There was a considerable amount of behavioral trial and error and improvisation in what organizational officials attempted in the immediate periods after the two earthquakes. To be sure, there were at times efforts to obtain directives and guidance from traditional sources within organizations which would have been used on an everyday basis. But such attempts were not often successful. This often led then to initiation of considerable communication within and outside the organization in an attempt to obtain relevant information. In turn this led to decisions being made and actions being undertaken which were frequently rather untraditional for the officials and organizations involved. Put another way, while everyday bureaucratic norms and expectations were not totally put aside, deviations from the usual when necessary were undertaken to cope with the turbulent changes in the social environment.

How key organizational officials reacted in the Mexican earthquake is generally consistent with most of the relevant research literature (Dynes, 1987; Mileti and Sorensen, 1987; Quarantelli, 1988). Role incumbents can be expected to do their jobs, although in many cases there will be as there was in Mexico city, some psychological role strain. Role conflict will be behaviorally 
resolved in favor of the organization (see Dynes and Quarantelli, 1980). Officials in bureaucracies at least temporarily will change their work role behavior in the direction of more adaptive courses of action. Even bureaucrats and bureaucracies, at least at the height of the emergency period, will modify their behaviors in attempts to cope with a crisis occasion.

From a practical viewpoint, the observations in Mexico city are reassuring. Even without disaster planning, it can be assumed that at least key organizational personnel will generally do their jobs and adapt to the crisis setting. Good disaster planning, however, could serve to reduce some of the psychological or role strain that frequently occurs to such role incumbents in disasters. Similarly, even bureaucratic officials will often attempt to innovate in the face of group needs. But again good planning could teach officials how to improvise. Such planning should follow the model not of a script or a blueprint (where particular courses of action are specified) but of a map which usually shows a variety of different ways to go different places.

At a theoretical level, our finding indicates a need to better clarify the relationship between role incumbents maintaining their old roles and innovating new ones. As one summary of research results mostly from DRC studies concluded that:

...it has been found...that the less an organization has to change its predisaster functions and roles to perform in a disaster, the more effective is its disaster response. In essence, organizations whose daily operations can be switched to the topic of the emergency at hand do better than organizations who must adopt new operations:

but the authors go on also to note that:

organizations which are better able to vary from standard operating procedures during the disaster are typicaliy more effective than those who cannot be flexible...An organization which is rigid in structure... has a difficult time dealing with the uncertainty of disaster.... and adapting to its needs...to meet the challenge of performing new roles (Mileti and Sorensen, 1987: 20-21).

Just as we require a better understanding of the relationship between preparedness and emergence, we also need to obtain a clearer picture of the relationship between maintenance of traditional work roles and innovating on those roles in an emergency situation. 
5. There were organizational changes in disaster preparedness planning in the aftermath of the earthquake.

There have been relatively few studies of organizational change in the aftermath of disasters (Stallings, 1987: 253). But to the extent research exists, it shows that "organizational learning" which leads to structural and/or functional alterations with respect to preparedness planning, is rare. The literature indicates that after a major disaster, officials frequently talk about the need to institute or change the planning of their group. However, in the long run, few changes in either structure and/or functions are permanently instituted. (see, Adams, stallings and Vargo, 1970). It is even rarer for a new disaster oriented organization to be created. There are exceptions to be sure (see Anderson, 1969a; Forrest, 1979), but on the whole organizational change is not usually a consequence of a disaster.

In Mexico, in the aftermath of the earthquake the need for having overall disaster planning and improving the specific preparedness planning of particular organizations, was voiced. But contrary to the typical post recovery situation, major changes were instituted.

...the Government undertook to enhance
countrywide the static prevention of losses
from earthquakes and hurricanes, as well as
from other hazards by ordering a rapid
updating of building codes in all 32 states in
accordance with the latest results of
engineering research in Mexico and aboard.
Within a month of the 1985 earthquake an
Emergency Building Code was adopted for Mexico
City (Jakob, 1989: 3-4).

In fact, by late 1988 draft codes had been prepared for all other states under the coordination of a National coordination committee.

Concurrently, a National System of Civil protection was projected and provided with a coherent institutional and legal framework. A working group was set up in 1986 with the specific objective of defining the institutional and operational conditions required for the creation of a national civil defense system. Also:

Early in 1989 the works done by this committee led to the present administration's decision to create within the Department of Interior... a Directorate specifically in charge of all matters of civil defense... The responsibilities which this new entity has been assigned, are--first--to prepare and/or help prepare appropriate and institutionally and technically coherent policy approaches to problems of hazard prevention and mitigation 
at the level of Federal, state and local governments, and--second--to oversee and where necessary, ensure interinstitutional coordination of all activities related to mitigation and emergency assistance in the case of occurred disasters (Jakob, 1989: 5).

The institutional entity created:

would in particular be in charge of ensuring the compliance with civil defense requirements of new public and private industrial, commercial, social and residential investment, preparing contingency plans for hazardous industrial plants, and assisting public and private sector entities in establishing guidelines for emergency situations (Jakob, 1989: 5).

Organizational modifications were also instituted below the federal level and within the private sector. For example, specific groups such as the Red Cross (see Drabek, 1989) and the metro system changed the disaster preparedness stance of their agencies. Additionally, new linkages between organizations were created to improve disaster planning.

From a practical point of view, our observations that post recovery organizational disaster planning can occur, is encouraging. It indicates to those officials and those organizations who are interested in change, that it is possible to alter predisaster structures and functions. The research literature is replete with admonitions for planners and operational personnel to take "advantage" of a disaster to bring about alterations and modifications to improve the planning in place. Mexico City shows that a window of opportunity provided by a disaster can be used. Recovery measures can be employed for mitigation purposes.

From a more theoretical viewpoint, the organizational change that did occur after the earthquake suggests that there is a need to better understand what will activate a "political will" to do something. It has long been known that simply having an experience of a disaster does not in itself create the sufficient conditions to generate changes in community and group structures and functions (Weller, 1974). Stallings points to one possible initial point of attack on the problem:

Environmental variables are the key to explanations of organizational change whether short-term, temporary alterations or longerterm, permanent change...rational adaptation theory...posits that organizational change in the form of internal structural adjustments is the result of deliberate human decisions 
intended to better position the organization

in its environment (Stallings, 1987: 241).

But if this is so, we need to learn more about the specific political circumstances which are required to alter system and organizational aspects in the way they did in Mexico.

overall, our study found both differences and similarities between what the research literature indicates about organizational responses to disasters and what happened in Mexico City. Some possible reasons that might be involved in this we have discussed in our larger report (see Dynes, Quarantelli and Wenger, 1990). However, in the long run the answer will only be found by further systematic studies which will allow a separating out of what might be country or societally specific from what might be rather universal behavior in such crisis occasions. Hopefully the work we have reported here can provide an initial framework and a beginning model, as well as specific hypotheses, for even better crosssocietal studies. (see Dynes, 1988 for a discussion of the limited amount of social research on disasters that is truly of a cross comparative nature). 


\section{REFERENCES}

(no author) 1954

A preliminary report on the Bakersfield, California earthquake, August 22, 1951. In E. Marks and C. Fritz et al. Human Reactions in Disaster Situations, Volume 3. Chicago: National Opinion Research Center, University of Chicago: 96-103.

Adams, David, R. Stallings and S. Vargo

1970 Natural disaster and organizational change. Newark: Disaster Research Center, University of Delaware.

Anderson, William

1969 a Disaster and organizational Change: A Study of the Long-Term Consequences in Anchorage of the Alaska Earthquake. Newark, DE.: Disaster Research Center, University of Delaware.

Anderson, william

1969b "Social structure and the role of the military in natural disaster." Sociology and Social Research 53: 242-253.

Armillas, Ignacio

1989 Toward a methodology for seismic risk mitigation in urban planning. Pilot work in Mexico City. Unpublished paper.

Arnold, Christopher

1989 Urban earthquake hazards reduction: Society's needs--A U.S. perspective. In Proceedings of the 2nd Japan-United States Workshop on Urban Earthquake Hazards Reduction. Nagoya, Japan: UN Centre for Regional Development: 60-69.

Bohlen, Nina (compiler)

1986 Final Disaster Summary Report. Mexico 1985 Earthquake. Mexico City: AID office, US Embassy.

Britton, Neil 1987

Toward a reconceputalization of disaster for the enhancement of social preparation. In R. Dynes, B. De Marchi and C. Pelanda (eds.) Sociology of Disasters. Milan, Italy: Franco Angeli: 31-55.

Clifford, Roy 1956

The Rio Grande Flood: A Comparative Study of Border Communities. Washington: National Academy of Sciences.

Drabek, Thomas 
Institutional and political contexts. In Role stressors and Supports for Emergency Workers. Washington: US Government Printing Office: 60-75.

Drabek, Thomas 1986

Human System Responses to Disasters: An Inventory of Sociological Findings. NY: Springer-Verlag.

Drabek, Thomas $1987 a$

Emergent structures. In R. Dynes, B. De Marchi and C. Pelanda (eds.) Sociology of Disasters. Milan, Italy: Franco Angeli: 259-290.

Drabek, Thomas $1987 \mathrm{~b}$

Taxonomy and disaster: Theoretical and applied issues. In Gary Kreps (ed.) Social Structure and Disaster. Newark, DE.: University of Delaware Press: $317-345$.

Drabek, Thomas 1989

Some Lessons of Rehabilitation: Red Cross Responses to the 1985 Mexican Earthquakes. Final Report. Denver: Department of Sociology, University of Denver.

Dynes, Russell R. 1974

Organized Behavior in Disaster. Newark, DE.: Disaster Research Center, University of Delaware.

Dynes, Russell R. 1983

"Problems in emergency planning." Energy 8: 653660 .

Dynes, Russell R. 1987 The concept of role in disaster research. In $R$. Dynes, B. De Marchi and C. Pelanda (eds.) Sociology of Disasters. Milan, Italy: Franco Angeli: 71-102.

Dynes, Russell R. 1988

"Cross cultural international research: Sociology and disaster." International Journal of Mass Emergencies and Disasters 6: 101-129.

Dynes, Russell R. 1990

Community emergency planning: False assumptions and inappropriate analogies. Newark, DE.: Disaster Research Center, University of Delaware.

Dynes, Russell R. and Ben Aguirre 1979

"Organizational adaptation to crisis: Mechanisms of coordination and structural change." Disasters 3: 71-74.

Dynes, Russell R. and E. L. Quarantelli 
"Group behavior under stress: A required convergence of organizational and collective behavior perspectives." Sociology and social Research 52: 416-429.

Dynes, Russell R. and E. L. Quarantelli 1977 organizational Communications and Decision Making in Crises. Report Series \# 17 . Newark, DE.: Disaster Research Center, University of Delaware.

Dynes, Russell R. and E. L. Quarantelli 1980

Helping behavior in large scale disasters. In D. H. Smith and J. Macaulay (eds.) Participation in Social and Political Activities. San Francisco: Jossey Bass: 339-354.

Dynes, Russell R., E. L. Quarantelli and Gary Kreps 1981 A Perspective on Disaster Planning. Newark, DE.: Disaster Research Center, University of Delaware.

Dynes, Russell, E. L. Quarantelli and Dennis Wenger. Individual 1990 and organizational Response to the 1985 Earthquake in Mexico City. Newark, DE.: Disaster Research Center, University of Delaware.

Esteva, L.

1988 "The Mexican earthquake of September 19, 1985-Consequences, lessons, and impact on research and practice." Earthquake Spectra 4: 413-426.

Forrest, Thomas

1979 Hurricane Betsy 1965: A Selective Analysis of Organizational Response in the New Orleans Area. Newark, DE.: Disaster Research Center, University of Delaware.

Gratton, V., H. Thier, E. Arjonilla and R. Melgar 1987 "The recovery of schools from earthquake effects." Disasters 11: $310-316$.

Jakob, Felix A. 1989 Prevention and mitigation in Mexico. Unpublished paper.

Kennedy, will C. 1982

Organizational activity and the military in disaster operations in Chile in a 1965 earthquake: A historical case study. Newark, DE.: Disaster Research Center, University of Delaware.

Kreimer, Alcira 
The post earthquake reconstruction effort in Mexico. Unpublished paper.

Kreps, Gary

1984

Kreps, Gary 1985

"Sociological inquiry and disaster research." Annual Review of Sociology 10: 309-330.

"Disaster and the social order." Sociological Theory 3: 49-65.

Kreps, Gary (ed.)

1989

Social structure and Disaster. Newark, DE.: University. of Delaware Press.

Kreps, Gary 1990

(no author) 1985
Organizing for emergency management. In $T$. Drabek and G. Hoetmer (eds.) Principles and Practices of Emergency Management. Washington: The International City Management Association.

"Lessons from Mexico City." Update: Southern California Earthquake Preparedness Project $3: 1-8$.

Madrid, Miguel de la 1986

"Fourth State of the Nation Report." The Mexico City News Supplement september 2: 1-16.

Martin, James 1989

"Lessons learned: The Mexico City experience." Emergency Management Quarterly 3/4: 4-5.

McLuckie, Benjamin

1975 "Centralization and natural disaster response: A preliminary hypothesis and interpretations." Mass Emergencies 1: 1-9.

Mendez, Luis Lopeallera

1986 "Assistance for the Mexico City earthquake victims." Disasters 10: 25-26.

Mileti, Dennis and John Sorensen 1987

"Determinants of organizational effectiveness in responding to low probability catastrophic events." The Columbia Journal of World Business 22: 1-7.

Olson, Richard S. and Robert olson 1987

"Urban heavy rescue." Earthquake Spectra 5: 645658.

Pelanda, Carlo 
Disaster and sociosystemic vulnerability. In B. Jones and $M$. Tomazevic (eds.) Social and Economic Aspects of Earthquakes. Ithaca: Urban and Regional Studies Program, Cornell University: 67-91.

Perez, Hugo Garcia

1986 Mexico: The september earthquake, its consequences, rehabilitation and reconstruction. In International Seminar on Regional Development planning for Disaster Prevention. Nagoya, Japan: UN Centre for Regional Development: 1-40.

Quarantelli, E. L. 1966

organization under stress. In R. Brictson (ed.) Symposium on Emergency Operations. Santa Monica, CA.: System Development corporation: 3-19.

Quarantelli, E. L. $1984 \mathrm{a}$ Emergent Behavior at the Emergency Time Periods of Disasters. Final Project Report \#31. Newark, DE.: Disaster Research Center, University of Delaware.

Quarantelli, E. L. $1984 \mathrm{~b}$ L.
Inventory of Disaster Field Studies in the Social
and Behavioral Sciences 1919-1979. Newark, DE.:
Disaster Research Center, University of Delaware.

QuarantelIi, E. L. $1985 a$ Organizational Behavior in Disasters and
Implications for Disaster Planning. Newark, DE.:
Disaster Research Center, University of Delaware.

Quarantelli, E. I. $1985 b$

What is a disaster? The need for clarification in definition and conceptualization in research. In Barbara Sowder (ed.) Disasters and Mental Health: selected contemporary Perspectives. Rockville, MD.: National Institute of Mental Health: 41-73.

Quarantelli, E. L. 1987

"What should we study? Questions and suggestions for researchers about the concept of disasters." International Journal of Mass Emergencies and Disasters 5: 7.-32.

QuarantelIi, E. I. 1988

"Disaster crisis management: A summary of research findings." Journal of Management studies 25: 373385 .

QuarantelIi, E. L. 
1990 Thirty years of catastrophe research. In Patrick Lagadec (ed.) States of Emergency. London: Butterworth-Heinemann: 222-231.

QuarantelIi, E. L.

1992 Human behavior in the Mexico City earthquake: Basic themes from survey findings. Preliminary Paper \#185. Newark, DE.: Disaster Research Center, University of Delaware.

Quarantelli, E. L. and Russell R. Dynes

1977 "Response to social crisis and disaster." Annual Review of Sociology 2: 23-49.

(no author)

1986

The 1985 Mexico Earthquake. London: Reinsurance offices Association.

Robinson, Scott S., Y. Franco, R. Castrejon and H. Bernard

1986 It shook again--The Mexico City earthquake of 1985.

In Anthony Oliver-Smith (ed.) Natural Disasters and Cultural Responses Special Issue. Studies in Third World Societies 36: 81-121.

Stallings, Robert

1978 The structural patterns of four types of organizations in disasters. In E. L. Quarantelli (ed.) Disasters: Theory and Research. Beverly Hills, CA.: Sage: 87-103.

Stallings, Robert

1987 Organizational change and the sociology of disaster. In R. Dynes, B. De Marchi and C. Pelanda (eds.) Sociology of Disasters: Contributions of Sociology to Disaster Research. Milan, Italy: Franco Angeli: 239-258.

Stallings, Robert and E. L. Quarantelli

1985 "Emergent citizen groups and emergency management." Public Administration Review 45: 93-100.

Storlarski, Noemi and Benjamin Santa Maria

1987 Reconstruction after urban earthquakes: The case of Mexico city. following the 1985 earthquakes. Unpublished paper.

Thier, Herbert, Vivian Gratton and Fred Johnson

1986 Intentionality and Action: Schoolteachers' Perceptions and Expectations Following the 1985 earthquake. Boulder: Institute of Behavioral Science, University of Colorado. 

United Nations Economic Commission 1985 Damage Caused by the Mexican Earthquake and its Repercussions Upon the country's Economy. Santiago, Chile: Secretariat of the Economic Commission for Latin America.

Warheit, George and Russell R. Dynes 1968 The Functioning of Established organizations in Community Disasters. Newark, DE.: Disaster

Weick, Karl Research Center, University of Delaware. 1976

"Educational organizations as loosely coupled systems." Administrative Science Quarterly 21: 119.

Weller, Jack 1974

Organizational Innovation in Anticipation of Crisis. Newark, DE.: Disaster Research Center, University of Delaware.

Wenger, Dennis, E. L. Quarantelli and Russell Dynes

1986 Disaster Analysis: Emergency Management offices and Arrangements. Newark, DE.: Disaster Research Center, University of Delaware. 